\title{
Impact of hip fracture on hospital care costs: a population-based study
}

\author{
J. Leal ${ }^{1}$ - A. M. Gray ${ }^{1}$ - D. Prieto-Alhambra ${ }^{2,3,4}$ • N. K. Arden ${ }^{2,3}$ - C. Cooper ${ }^{2,3}$. \\ M. K. Javaid ${ }^{2,3}$ • A. Judge ${ }^{2,3}$ - The REFReSH study group
}

Received: 24 March 2015 / Accepted: 5 August 2015 / Published online: 19 August 2015

(C) The Author(s) 2015. This article is published with open access at Springerlink.com

\begin{abstract}
Summary Using a large cohort of hip fracture patients, we estimated hospital costs to be $£ 14,163$ and $£ 2139$ in the first and second year following fracture, respectively. Second hip and non-hip fractures were major cost drivers. There is a strong economic incentive to identify cost-effective approaches for hip fracture prevention.

Introduction The purpose of this study was to estimate hospital costs of hip fracture up to 2 years post-fracture and compare costs before and after the index fracture.

Methods A cohort of patients aged over 60 years admitted with a hip fracture in a UK region between 2003 and 2013 were identified from hospital records and followed until death or administrative censoring. All hospital records were valued using 2012/2013 unit costs, and non-parametric censoring methods were used to adjust for censoring when estimating average annual costs. A generalised linear model examined the main predictors of hospital costs.
\end{abstract}

J. Leal

jose.leal@dph.ox.ac.uk

1 Health Economics Research Centre, Nuffield Department of Population Health, University of Oxford, Old Road Campus, Headington, Oxford OX3 7LF, UK

2 Oxford NIHR Musculoskeletal Biomedical Research Unit, Nuffield Department of Orthopaedics, Rheumatology and Musculoskeletal Sciences, University of Oxford, Windmill Road, Headington, Oxford OX3 7LD, UK

3 MRC Lifecourse Epidemiology Unit, University of Southampton, Southampton General Hospital, Southampton SO16 6YD, UK

4 GREMPAL Research Group (Idiap Jordi Gol) and Musculoskeletal Research Unit (Fundació IMIM-Parc Salut Mar), Universitat Autònoma de Barcelona, Barcelona, Spain
Results A cohort of 33,152 patients with a hip fracture was identified (mean age 83 years (SD 8.2). The mean censoradjusted 1- and 2-year hospital costs after index hip fracture were $£ 14,163$ (95\% confidence interval (CI) $£ 14,008$ to $£ 14$, $317)$ and $£ 16,302$ (95\% CI $£ 16,097$ to $£ 16,515)$, respectively. Index admission accounted for $61 \%$ (£8613; $95 \%$ CI $£ 8565$ to $£ 8661$ ) of total 1 -year hospital costs which were $£ 10,964$ higher compared to the year pre-event $(p<0.001)$. The main predictors of 1-year hospital costs were second hip fracture, other non-hip fragility fractures requiring hospitalisation and hip fracture-related complications. Total UK annual hospital costs associated with incident hip fractures were estimated at $£ 1.1$ billion.

Conclusions Hospital costs following hip fracture are high and mostly occur in the first year after the index hip fracture. Experiencing a second hip fracture after the index fracture accounted for much of the increase in costs. There is a strong economic incentive to prioritise research funds towards identifying the best approaches to prevent both index and subsequent hip fractures.

Keywords Burden $\cdot$ Cost $\cdot$ Epidemiology $\cdot$ Health economics $\cdot$ Hip fracture $\cdot$ Osteoporosis

\section{Introduction}

Hip fractures are a major public health problem in terms of patient morbidity, mortality and costs to health and social care. The incidence of hip fracture increases steeply with age due to higher rates of osteoporosis and falls in the elderly population. Hip fractures account for the majority of osteoporotic fragility fractures and for over $40 \%$ of the estimated burden of osteoporosis worldwide [1]. In 2010, there were an estimated 600, 000 incident hip fractures in the European Union, costing $€ 20$ 
billion and accounting for $54 \%$ of the total costs of osteoporosis [2]. In the UK, the annual number of hip fractures is expected to increase from 79,000 to 104,000 by 2025 [2]. Existing estimates of the health and social care costs of hip fractures in the UK range from $£ 2$ billion to $£ 3$ billion [2, 3], but these were based on UK cost data that are over 10 years old $[2,4,5]$.

It is important to have robust and up-to-date evidence of the economic impact of hip fracture and its main drivers. Such data are essential to inform decisions about changes in health service delivery aimed at achieving greater efficiency and better patient care. Furthermore, such information is key to investment and disinvestment decisions regarding new osteoporosis and hip fracture prevention interventions as these are driven by cost-effectiveness analysis [6], where a key input is the long-term cost of hip fracture.

The primary aim of this study is to estimate the hospital costs of hip fracture up to 2 years post event for both index fracture and subsequent fracture, using a large patient-level dataset representative of the UK hip fracture population. Secondly, we compare hospital costs before and after the event to explore the impact of significant co-morbidities in individuals with hip fracture. Finally, we report the main predictors of hospital costs following hip fracture.

\section{Methods}

\section{Setting and data sources}

This study adopted an incidence-based approach to estimate the secondary care costs associated with hip fracture. Data were obtained from the Hospital Episode Statistics (HES) database for a representative region of the UK covering a population of around 4 million people and with 11 National Health Service (NHS) hospitals treating fragility fractures [7]. This database captures all hospital NHS patient care, as well as private patients treated in NHS hospitals and care delivered by treatment centres (including private providers) funded by the NHS. It contains anonymised patient administrative information (such as date of admission and discharge, admission method, age, gender and length of stay), diagnosis (ICD-10) and procedures codes (OPCS-4). We extracted inpatient care data from April 1999 to March 2013, hospital outpatient activity from April 2003 and accident and emergency attendances from April 2007. Deaths were obtained from the linked HES and the Office of National Statistics (ONS) mortality database, which captures deaths occurring in and out of hospital.

\section{Study participants}

We identified HES records for all patients over 60 years of age who had had an emergency hospital admission with a primary
ICD-10 diagnosis code for hip fracture (S72.0, S72.1, S72.2, S72.9) between April 2003 and March 2013. We extracted all HES records before and after that admission. A number of exclusion criteria were applied to minimise misclassification: (1) day cases were excluded by imposing a condition that patients had to stay at least one night in hospital, unless death occurred in the first $24 \mathrm{~h}$ of admission; (2) individuals who had had a previous hip fracture between April 1999 and March 2003 were excluded to reduce duplicate coding of hip fractures that occurred before the period of analysis but led to repeat hospital admissions due to complications or unresolved sequelae; and (3) patients were also excluded if they had had a hip fracture due to trauma, such as transport accidents using ICD-10 codes (V01-V99).

When estimating hospital costs in the year before and after fracture, we included only patients with an index admission after 1 April 2008, to ensure that outpatient and emergency attendances costs would be included. We refer to this set of results as 'total hospital' costs and contacts. Conversely, we used the whole HES dataset (April 2003 to April 2013) to report costs due to hospitalisation, critical care and day cases, and benefit from the increased statistical power. We refer to these results as 'hospitalisation' costs.

\section{Ascertainment of subsequent fracture/s}

Subsequent hip fracture/s were identified using the same approach as for the index fracture. However, to ensure this was a separate fracture and not hospital re-admissions due to adverse effects of the index fracture, we counted second hip fractures only if admitted in a separate 'continuous inpatient spell' (CIPS) from index admission and at least 30 days after admission for the primary fracture. A CIPS is made up of one or more hospital spells (i.e. time patient stays in one hospital) and is defined as a continuous period of care within the NHS, regardless of any transfers to another hospital. A hospital spell starts with the index admission, involves treatment by one or more consultants (i.e. finished consultant episodes-FCE) and ends when the patient dies or is discharged from hospital [8].

\section{Ascertainment of surgery and mortality}

All-cause mortality was estimated at 30 days and 1 year from the day of emergency admission due to hip fracture and using the date of death from the ONS mortality database. We also ascertained whether patients were recorded as having surgery during the initial hospital spell following hip fracture. Surgery was identified using OPCS-4 codes for fixation (W19, W20, W22, W24 and W25 covering open or close reduction and internal or external fixation), prosthetic replacement of the head of the femur (W46, W47, W48) and total hip replacement (W37, W38, W39, W93, W94, W95). We also examined the side of the first and subsequent hip fractures managed with 
surgery using OPCS-4 codes (Z941 for bilateral operation, Z942 for right-side operation and Z943 for left-side operation).

\section{Costs}

Each finished consultant episode (FCE) in a hospital spell was assigned into a Healthcare Resource Group (HRG) via the 2012/13 Casemix Grouper Software (HRG4+) [9]. HRGs are standard groups of clinically similar treatments that consume a common set of healthcare resources. We did not separate acute care from rehabilitation admission as, in the UK, rehabilitation generally starts following acute care in the general ward, in which patients may stay for weeks or be admitted later into specialist rehabilitation wards or community hospitals. All resource use was valued using 2012-2013 prices that were obtained from the schedule of reference costs for NHS trusts [10]. The costs for inpatient stay and outpatient visits include the costs of treatment and diagnostic interventions. Total costs per patient were aggregated into monthly and annual amounts for the purposes of the analysis.

\section{Statistical analysis}

The HES database was censored in March 31, 2013, and complete follow-up was not available for all cases. Hence, we report total hospital costs for those patients with complete follow-up data at years 1 and 2 following hip fracture and for the whole sample after adjusting for censoring using the methodology developed by Lin et al. [11]. This involved dividing the study period into days and estimating the mean daily costs across all patients who are alive at the beginning of a given day, i.e. complete cases. The mean daily costs were then multiplied by the Kaplan-Meier survival probability of being alive at the beginning of each day and summed over the entire period of interest (i.e. 1 and 2 years) to obtain the mean censor-adjusted costs. Costs are reported as means together with their $95 \%$ confidence intervals (CIs), obtained from 1000 bootstrap estimates.

We determined the marginal costs from hip fracture by comparing costs in the year before and after the index hip fracture. The national total annual hospital costs of hip fracture were determined by multiplying the incidence of hip fracture in the UK $(79,243$ in 2010) by the estimated costs per hip fracture [2] .

Predictors of hospitalisation costs of hip fracture were estimated using a generalised linear model (GLM). After reviewing the literature, we examined the following predictors of costs in the year of the hip fracture: age at fracture; type of fracture (head and neck: S72.0; pertrochanteric: S72.1; subtrochanteric: S72.2; unspecified: S72.9); gender; Charlson co-morbidity score (complications at fracture and occurring up to 3 years before fracture) [12]; place of residence pre- and post-fracture (own home or care home: residential or nursing home); occurrence of second hip fracture; history of other osteoporotic major fragility fractures requiring hospitalisation pre- and post hip fracture (spine, wrist, pelvis, rib, humerus and other identified with ICD-10 diagnosis codes: S22, S32, S42, S52.0-S52.3, S22.5 and S22.6); primary hip replacement and revision [13]; complications of internal orthopaedic devices (ICD-10 code: T84) and infection or haemorrhage following procedure (T81.0 and T81.4); dislocation (M24.3 and M24.4); malunion and non-union of fracture (M84.0-M84.2); periprosthetic fracture (M96.6); other/ unspecified postprocedural musculoskeletal disorders (M96.8, M96.9); sequelae of fractures of the femur (T93.1); hip luxations (S73.0); ethnicity (white and non-white); year of hip fracture; allcause mortality within 30 days and between days 31 days and 1 year; and income deprivation measured by the index of multiple deprivation. The choice of the GLM model family and link functions was informed by the modified Park test and the BoxCox test, respectively. Model fit was assessed using Pregibon's Link test, and different family and link functions were compared using Akaike's information criterion. Univariate analyses in continuous variables were performed using Student $t$ tests. A variable was deemed to be statistically significant if $p<0.01$ to account for the large sample size, and 95\% CI were reported for ease of comparison with other studies. All analyses were performed using STATA version 12 (StataCorp, College Station, TX).

\section{Results}

\section{Patient sample}

Between April 1, 2003, and March 31, 2013, 33,152 patients were identified as having had a hip fracture. Mean age of the sample was 83 years (SD 8.2) and $75 \%$ were female. The majority of the population was of white ethnicity. Baseline characteristics of the study participants are shown in Table 1. Women were older than men (+2.0 years) and less likely to have a history of complications (CCI score of 1.1 vs. 1.7 in men) at index hip fracture.

\section{Patient outcomes and hospitalisation costs}

The average follow-up of the cohort was 2.6 years (median 1.8 years; SD 2.5; range $0-10$ years) from index hip fracture, during which time $6.6 \%$ of patients suffered a second hip fracture (Table 2). The proportion of patients recorded as receiving hip surgery was $93.1 \%(n=30,858)$ and $90 \%(n=$ 1987) at index and second hip fracture, respectively. Of patients with a second hip fracture, $83.3 \%(n=1837)$ had both surgery and side of surgery recorded at the first and second hip fracture. Only $6.3 \%(n=1721)$ of these subset of patients were recorded as having a second hip fracture on the same side as the index fracture. In terms of the initial hospital admission, no significant difference was found in length of stay between patients with a second hip fracture on the same side of the 
Table 1 Patient characteristics at index hip fracture

\begin{tabular}{|c|c|}
\hline Age, mean (SD) & $82.7(8.2)$ \\
\hline \multicolumn{2}{|l|}{ Type of hip fracture, $n(\%)$} \\
\hline Fracture of head and neck of femur (S72.0) & $25,335(76.4 \%)$ \\
\hline Pertrochanteric fracture (S72.1) & $6590(19.9 \%)$ \\
\hline Subtrochanteric fracture (S72.2) & $913(2.8 \%)$ \\
\hline Unspecified fracture of femur (S72.9) & $315(1.0 \%)$ \\
\hline Males, $n(\%)$ & $8355(25.2 \%)$ \\
\hline White ethnicity ${ }^{\mathrm{a}}$ & $31,287(98.9 \%)$ \\
\hline \multicolumn{2}{|l|}{ Index of multiple deprivation (IMD) score } \\
\hline Multiple deprivation, mean (SD) ${ }^{\mathrm{b}}$ & $13.4(10.4)$ \\
\hline Income deprivation, mean $(\mathrm{SD})^{\mathrm{c}}$ & $0.094(0.0729)$ \\
\hline Mean Charlson co-morbidity index, mean (SD) & $1.26(1.57)$ \\
\hline Median (interquartile range) & $1(0-2)$ \\
\hline Score $0-2, n(\%)$ & $27,379(82.6 \%)$ \\
\hline Score 3-4, $n(\%)$ & $4071(12.3)$ \\
\hline Score 5 or higher, $n(\%)$ & $1702(5.1 \%)$ \\
\hline \multicolumn{2}{|l|}{$\begin{array}{l}\text { History of complications recorded in } \\
\text { previous hospitalisations, } n(\%)\end{array}$} \\
\hline Dementia & $6101(18.4 \%)$ \\
\hline Pulmonary disease & $4594(13.9 \%)$ \\
\hline Diabetes & $3841(11.6 \%)$ \\
\hline Stroke & $3163(9.5 \%)$ \\
\hline Myocardial infarction & $3068(9.3 \%)$ \\
\hline Cancer & $2895(8.7 \%)$ \\
\hline \multicolumn{2}{|l|}{ Source of admission at index fracture, $n(\%)$} \\
\hline Own home & $27,985(84.4 \%)$ \\
\hline Nursing/residential/temporary accommodation & $3681(11.1 \%)$ \\
\hline Another hospital & $1415(4.4 \%)$ \\
\hline Unknown & $35(0.1 \%)$ \\
\hline
\end{tabular}

index fracture and those with a fracture on the opposite side ( 2.8 additional days, $95 \% \mathrm{CI}-0.7$ to 6.2 days).

Mortality at 30 days and 1 year following index fracture was estimated to be 9.4 and $31.2 \%$, respectively. Within 30 days of the index fracture, the age-standardised proportion of patients who died was $14.2 \%$ amongst male patients and $7.9 \%$ amongst female patients (using the direct standardisation method and the age distribution of the whole hip fracture sample). Within 1 year of the index fracture, the age-standardised mortality amongst male and female patients was estimated to be 42.3 and $27.5 \%$, respectively. After index fracture, the majority of patients were recorded as being discharged to their own home (49 \%), or transferred to another hospital (23\%) or to a care home $(18 \%)$. Ten percent of patients died in hospital during the index admission. The number of patients in a care home increased to $24 \%$ after 1 year of complete follow-up. In contrast, after a second hip fracture, $32 \%$ of patients were
Table 2 Patient outcomes and hospitalisation costs after index hip fracture

Follow-up time in years, mean (SD) 2.6 (2.5)

Second hip fracture, $n(\%)$

$2206(6.6 \%)$

Time to second hip fracture in years, mean (SD) $2.2(2.0)$

Surgery or implant-related complications $\mathrm{s}^{\mathrm{a}}, n(\%)$

Within index fracture hospital

$1015(3.1 \%)$

Within 1 year of fracture ${ }^{\mathrm{b}}$

$1942(6.4 \%)$

Hip replacement surgery ${ }^{\mathrm{c}}, n(\%)$

Within index fracture hospitalisation $\quad 1522(5.0 \%)$

Within 1 year of fracture ${ }^{\mathrm{b}}$

$1781(5.9 \%)$

Hip revision surgery ${ }^{\mathrm{c}}, n(\%)$

Within index fracture admission $\quad 247(0.7 \%)$

Within 1 year of fracture ${ }^{\mathrm{b}} \quad 463(1.5 \%)$

Mortality, $n(\%)$

Within 30 days $^{\mathrm{d}}$

Within 1 year $^{\mathrm{b}}$

$3101(9.4 \%)$

$9492(31.2 \%)$

Discharge destination following index

fracture admission, $n(\%)$

Own home

$16,126(48.6 \%)$

Care home or temporary accommodation

$5957(18.0 \%)$

NHS hospital

$7453(22.5 \%)$

Unknown

$371(1.1 \%)$

Dead

$3245(9.8 \%)$

Living in a care home within 1 year of index fracture ${ }^{\mathrm{b}}$

Newly transferred to a care home within 1 year of index fracture ${ }^{\mathrm{b}}$ (living in different setting prior to hip fracture)

Total length of hospital stay within 1 year of fracture $^{\mathrm{b}}$, mean (SD)

Initial hospitalisation $20.5(20.0)$

Emergency hospitalisations after discharge

$6.9(19.0)$

Non-emergency hospitalisations after discharge

$11.3(28.6)$

Total

$38.6(41.2)$

Hospital inpatient re-admissions within 1 year of fracture ${ }^{b}$

Emergency, mean (SD)

$0.5(0.9)$

Non-emergency, mean (SD)

$0.4(0.9)$

Total, mean (SD)

$0.9(1.4)$

Initial hospitalisation costs (index admission to discharge)

Primary hip fracture, mean (SD)

$£ 8663$ (4605)

Second hip fracture, mean (SD)

$£ 8544$ (4178)

Hospitalisation costs within 1 year of fracture ${ }^{\mathrm{b}}$

Emergency-related costs, mean (SD)

$£ 10,854(7268)$

Non-emergency-related costs, mean (SD)

$£ 2972$ (7896)

Total, mean (SD)

$£ 13,82611,016$

Hip fracture-related hospitalisation costs within 1 year of admission ${ }^{\mathrm{b}}$, mean $(\mathrm{SD})$

$£ 10,375$ (6962)

${ }^{\mathrm{a}}$ ICD-10 codes T81.0, T81.4 and T84

${ }^{\mathrm{b}}$ Cases with complete follow-up, including those who died in that year $(n=30,430)$

${ }^{\mathrm{c}}$ Using OPCS codes defined by the National Joint Registry [13]

${ }^{\mathrm{d}}$ Cases with complete follow-up during the 30 days $(n=32,989)$ 
discharged to a care home after hospital discharge, which increased to $40 \%$ amongst patients with at least 1 year of followup. Hospital re-admissions for any reason with inpatient stay in the year following the index hip fracture totalled 0.9 (median 0 , SD 1.4, IQR 0-19) per patient or 1.8 (median 1, SD 1.6, IQR 1-19) per patient re-admitted. Of these re-admissions, $57 \%$ were emergency admissions and accounted for 18.1 (median 0, SD 35.9, IQR 0-22) additional days in hospital per patient or 37.2 (median 23, SD 43.9, IQR 8-50) additional days per patient re-admitted. About $50 \%$ of diagnosis codes in nonemergency inpatient admissions following index admission were hip fracture related.

The hospitalisation costs associated with index admission for primary hip fracture were $£ 8663$ (median $£ 8049$, SD 4605) compared to $£ 8544$ (median $£ 8049$, SD 4112) for the second hip fracture. Length of stay in the index admission was 20.5 (median 14, SD 20.0, IQR 9-307) and 20.8 (median 15, SD 18.8, IQR 9139)days for primary and second hip fracture, respectively. For patients suffering a subsequent hip fracture $(6.6 \%)$, the hospital admission following the second hip fracture resulted in significantly higher length of stay (2.0 days, $p<0.001,18.8$ vs. 20.8 days) and costs ( $£ 406, p<0.001, £ 8138$ vs. $£ 8544)$ relative to the index fracture. Within the first year following primary hip fracture, the total hospitalisation costs were estimated to be $£ 13$, 826 (median $£ 10,425$, SD 11,016), of which $75 \%$ were due to hip fracture-related admissions ( $£ 10,375$, median $£ 8050)$. Hospitalisation costs and length of stay were highly correlated (Spearman correlation coefficient $0.82, p<0.001$ ).

Figure 1 reports the hospitalisation costs in the months before and after primary hip fracture. The annual cost in the year of the fracture was estimated to be $£ 10,860$ (95\% CI $£ 10$, 710 to $£ 11,011$ ) higher compared to that of the previous year. The highest costs occur in the first 6 months post hip fracture, dropping sharply afterwards to pre-fracture levels of expenditure and remaining fairly constant throughout the second year post-fracture. The 2-year survivors show a similar pattern of costs relative to all patients. However, while the costs in the second year after hip fracture remain numerically higher than in the year pre-fracture $(£ 112,95 \% \mathrm{CI}-£ 29$ to $£ 274)$, this was not statistically significant.

\section{Total hospital costs before and after index fracture}

Forty-four percent $(n=14,552)$ of patients had a primary hip fracture after 1 April 2008 and complete 1-year follow-up. They were used to compare hospital resource use and total costs in the years before and after the fracture (Table 3). In the year following hip fracture, patients had 1.03 additional hospital admissions (i.e. inpatient stay, day cases and regular day/night attenders) $(p<0.001), 27.9$ additional hospital inpatient days $(p<0.001), 0.54$ additional accident and emergency contacts $(p<0.001)$ and 0.01 additional outpatient visits $(p<0.001)$ compared with the previous year.
Including both outpatient and emergency contacts, the total costs were estimated at $£ 14,264$ in the year of the fracture, of which $96 \%(£ 13,635)$ were due to inpatient stay and critical care. Unadjusted for other covariates, men had significantly higher total hospital costs compared to women (£1188, $p<0.001$ ). Having a hip fracture resulted in additional costs of $£ 10,964$ (95\% CI $£ 10,767$ to $£ 11,161$ ) compared to the year prior to hip fracture. Adjusting for censoring, the 1-year costs were similar to the complete-case analysis at $£ 14,163$ (95\% CI $£ 14,008$ to $£ 14,317)$. The costs in the first 2 years following hip fracture (2-year) adjusted for censoring were $£ 16,302$ (95\% CI $£ 16,097$ to $£ 16,515$ ) compared to $£ 16,270$ using only the complete cases $(n=12,155)$. Conditional on surviving the year following hip fracture, hospital costs were $£ 3072$ in the second year using only the complete cases $(n=7624)$.

\section{Annual hospital cost of hip fractures in the UK}

The total annual hospital costs associated with all incident hip fractures in the UK amongst those aged $50(n=79,243)$ were estimated at $£ 1130$ million. Considering only the costs attributable to hip fracture (marginal), hip fracture was estimated to cost $£ 869$ million per year (Table 4).

\section{Predictors of hospitalisation costs in the first year following hip fracture}

The predictors of hospitalisation costs are shown in Table 5. A GLM model with gamma family and identify link function had the best fit. Adjusting for all covariates, men had higher hospitalisation costs than women (£910, $95 \%$ CI $£ 679$ to $£ 1141$ ) and higher length of stay (4.5 days). Furthermore, costs were positively associated with age ( $£ 45$ per additional year) and inversely associated with income, with costs rising with income deprivation. A higher Charlson co-morbidity score at index hip fracture increased hospitalisation costs by approximately $£ 694$ per additional unit of the Charlson score. Transiting to a care home for the first time after index fracture was associated with higher hospital costs (£5583; $95 \% \mathrm{CI}$ $£ 5197$ to $£ 5970$ ) and a longer length of stay (22 days) relative to patients who went back to their previous accommodation, possibly indicating poorer health.

Holding all else constant, having a second hip fracture within the same year as the primary one was associated with an additional $£ 9198$ (95 \% CI £8059 to £10,337) expenditure in hospitalisation costs. Major (non-hip) fragility fractures requiring hospitalisation post hip fracture were also found to be significantly associated with higher hospitalisation costs $(£ 5705$, $95 \%$ CI: $£ 4434$ to $£ 6975$ ). Amongst hip fracture-related complications, surgical complications within and after index admission were the most frequently reported and were associated with higher costs and length of stay (22 and 25 days, respectively) relative to no complications. Periprosthetic fracture was also 
Fig. 1 Hospitalisation costs in the months before and after primary hip fracture. Legend: *Complete cases, including those who died in that year

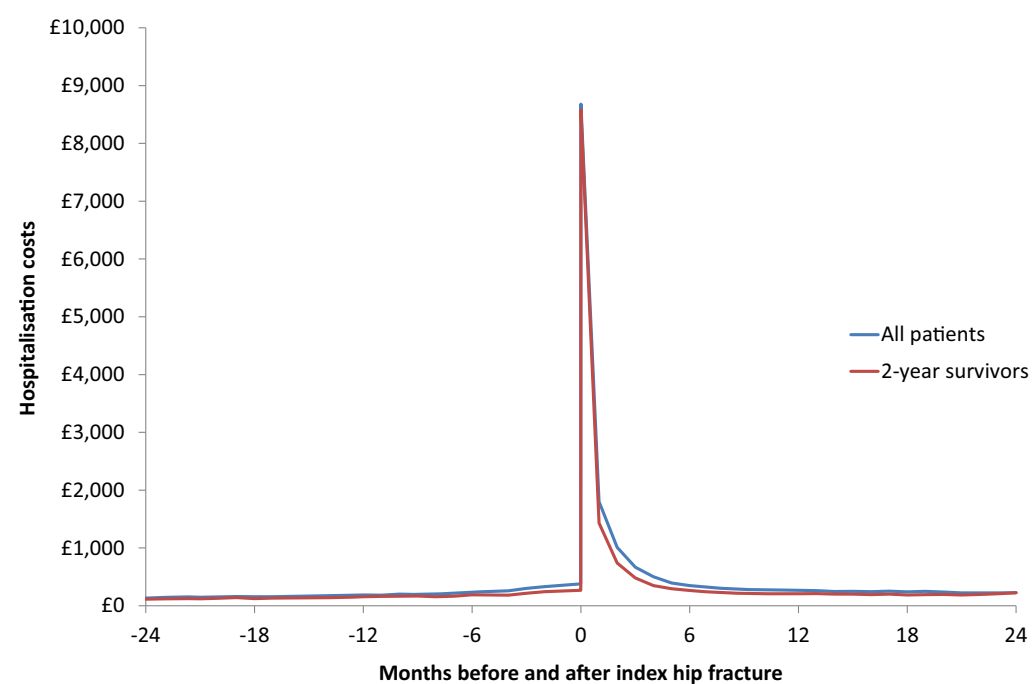

\begin{tabular}{|c|c|c|c|c|}
\hline & 2 years before & Year before & Year 1 & Year 2 \\
\hline $\begin{array}{l}2 \text { year survivors } \\
\text { vs year before }\end{array}$ & $£ 1,561$ & $£ 2,258$ & $f 13,231$ & $£ 2,380$ \\
\hline \multirow[t]{2}{*}{ Difference } & $\begin{array}{c}-£ 697 \\
(-1980 \text { to }-1839)\end{array}$ & - & $\begin{array}{c}£ 10,974 \\
\text { (10772 to } 11175)\end{array}$ & $\begin{array}{c}f 122 \\
\text { (-29 to } 274)\end{array}$ \\
\hline & $N=15,787$ & $N=15,787$ & $N=15,787$ & $\mathrm{~N}=15,787$ \\
\hline $\begin{array}{l}\text { All patients* vs } \\
\text { year before }\end{array}$ & $£ 1,906$ & $£ 2,966$ & $£ 13,829$ & $£ 2,775$ \\
\hline \multirow[t]{2}{*}{ Difference } & $\begin{array}{c}-£ 1,060 \\
(-946 \text { to }-1174)\end{array}$ & - & $\begin{array}{c}£ 10,860 \\
(10709 \text { to } 11011)\end{array}$ & $\begin{array}{c}-£ 192 \\
(-56 \text { to }-328)\end{array}$ \\
\hline & $\mathrm{N}=30,430$ & $\mathrm{~N}=30,430$ & $\mathrm{~N}=30,430$ & $\mathrm{~N}=18,541$ \\
\hline
\end{tabular}

associated with significantly higher hospitalisation costs relative to patients without this, at $£ 9569$ (95\% CI $£ 6302$ to $£ 12,835$ ).

Finally, patients who died within 30 days were associated with lower hospitalisation costs $(-£ 4672 ; 95 \% \mathrm{CI}-$ $£ 4906$ to $-£ 4437$ ), mostly as a result of lower length of stay than those who survived the first 30 days (mean of 11.3 vs. 41.9 days). Patients who died after 30 days had higher costs (£2549; $95 \%$ CI £2246 to £2853) than the survivors, again mostly due to a longer length of stay (mean of 53.2 days vs. 38.3 days).

\section{Discussion}

In this study, we estimated the immediate- and medium-term (up to 2 years) hospital costs of hip fracture in a large representative sample of patients in the UK, adjusted for hospital use prior to the index fracture, explored the main variables influencing these costs, and estimated the attributable costs of all hip fractures in the UK. We also identified the second hip fracture within the first year of index fracture as a major predictor of additional cost.

Table 3 Resource use and costs in the year prior to and after hip fracture (April 2008-May 2013)

\begin{tabular}{|c|c|c|c|c|c|c|}
\hline & Total & $\mathrm{A} \& \mathrm{E}$ & Outpatient care & Inpatient care & $\begin{array}{l}\text { Length of } \\
\text { stay }\end{array}$ & $\begin{array}{l}\text { Sample } \\
\text { size }\end{array}$ \\
\hline \multicolumn{7}{|l|}{ Resource use, annual } \\
\hline Before index fracture & - & 0.71 & 3.10 & 1.20 & 8.29 & 14,552 \\
\hline After, complete cases ${ }^{\mathrm{a}}$ & - & 1.26 & 3.13 & 2.23 & 36.14 & 14,552 \\
\hline Difference, after vs. before & - & $0.54 * *$ & $0.03 * *$ & $1.03 * *$ & $27.85^{* *}$ & \\
\hline \multicolumn{7}{|l|}{ Hospital costs, annual } \\
\hline Before index fracture & $£ 3299$ & $£ 105$ & $£ 295$ & $£ 2899$ & - & 14,552 \\
\hline After, complete cases ${ }^{\mathrm{a}}$ & $£ 14,264$ & $£ 202$ & $£ 297$ & $£ 13,765$ & - & 14,552 \\
\hline Difference, after vs. before & $£ 10,964 * *(10,767$ to 11,161$)$ & $£ 96 * *$ (93 to 101$)$ & $£ 2(-9$ to 12$)$ & $£ 10,865^{* *}(10,671$ to 11,060$)$ & - & \\
\hline After, censor-adjusted & $£ 14,163(14,008$ to 14,317$)$ & $£ 207$ (204 to 210$)$ & $£ 303$ (293-313) & $£ 13,653(13,501$ to 13,812$)$ & - & 17,274 \\
\hline
\end{tabular}

${ }^{\text {a }}$ Complete cases including those who died in given year

$* * p<0.001$ 
Table 4 Total annual hospital costs associated with hip fractures in the UK

\begin{tabular}{lll}
\hline & Absolute $^{\mathrm{a}}$ & Marginal $^{\mathrm{b}}$ \\
\hline Annual incident hip fractures in the UK & 79,243 & 79,243 \\
Accident and emergency cost per hip fracture, $£$ & $£ 202$ & $£ 96$ \\
Outpatient cost per hip fracture, $£$ & $£ 297$ & $£ 2$ \\
Hospitalisation cost per hip fracture, $£$ & $£ 13,765$ & $£ 10,865$ \\
Annual total hospital cost per incident hip fracture, $£$ & $£ 14,264$ & $£ 10,964$ \\
Total cost, $£$ million & $£ 1130$ & $£ 869$ \\
\hline
\end{tabular}

${ }^{a}$ Absolute denotes 1-year costs following hip fracture

${ }^{\mathrm{b}}$ Marginal denotes the difference in 1-year costs relative to the year before the hip fracture
Table 5 Predictors of 1year hospitalisation costs after index hip fracture

\begin{tabular}{|c|c|c|c|c|c|}
\hline & Frequency & Mean & Low $95 \%$ CI & High $95 \%$ CI & $p>z$ \\
\hline \multicolumn{6}{|l|}{ Type of hip fracture } \\
\hline Head and neck & $76.9 \%$ & Reference & & & \\
\hline Pertrochanteric & $19.4 \%$ & $-£ 266$ & $-£ 505$ & $-£ 28$ & 0.029 \\
\hline Subtrochanteric & $2.7 \%$ & $£ 491$ & $-£ 137$ & $£ 1119$ & 0.125 \\
\hline Unspecified & $1.0 \%$ & $£ 610$ & $-£ 432$ & $£ 1653$ & 0.251 \\
\hline \multicolumn{6}{|l|}{ Gender } \\
\hline Female & $74.8 \%$ & Reference & & & \\
\hline Male & $25.2 \%$ & $£ 910$ & $£ 679$ & $£ 1141$ & $<0.001$ \\
\hline Age at hip fracture (centred on 82 years) & & $£ 47$ & $£ 35$ & $£ 60$ & $<0.001$ \\
\hline Year at hip fracture (centred on year 2008) & & $-£ 99$ & $-£ 135$ & $-£ 63$ & $<0.001$ \\
\hline Indices of income deprivation $(\times 100)$ & & $£ 31$ & $£ 18$ & $£ 45$ & $<0.001$ \\
\hline $\begin{array}{l}\text { Charlson co-morbidity score } \\
\text { (up to } 3 \text { years prior fracture) }\end{array}$ & & $£ 695$ & $£ 622$ & $£ 768$ & $<0.001$ \\
\hline Death within 30 days of hip fracture & $10.2 \%$ & $-£ 4672$ & $-£ 4906$ & $-£ 4437$ & $<0.001$ \\
\hline Death between 31 days and 1 year & $21.5 \%$ & $£ 2549$ & $£ 2246$ & $£ 2853$ & $<0.001$ \\
\hline Living in care home before hip fracture & $9.6 \%$ & $-£ 595$ & $-£ 896$ & $-£ 294$ & $<0.001$ \\
\hline Moving to care home after hip fracture (new) & $16.1 \%$ & $£ 5583$ & $£ 5197$ & $£ 5970$ & $<0.001$ \\
\hline Second hip fracture & $2.7 \%$ & $£ 9198$ & $£ 8059$ & $£ 10,337$ & $<0.001$ \\
\hline $\begin{array}{l}\text { Major fragility fracture requiring } \\
\text { hospitalisation post hip fracture }\end{array}$ & $1.5 \%$ & $£ 5705$ & $£ 4434$ & $£ 6975$ & $<0.001$ \\
\hline $\begin{array}{l}\text { Surgical complications within index } \\
\text { admission }^{\text {a }}\end{array}$ & $3.1 \%$ & $£ 5694$ & $£ 4849$ & $£ 6538$ & $<0.001$ \\
\hline $\begin{array}{l}\text { Surgical complications after discharge } \\
\text { from index admission }\end{array}$ & $3.3 \%$ & $£ 10,552$ & $£ 10,352$ & $£ 10,753$ & $<0.001$ \\
\hline Malunion and non-union of fracture ${ }^{\mathrm{b}}$ & $0.5 \%$ & $£ 4613$ & $£ 2396$ & $£ 6830$ & $<0.001$ \\
\hline Periprosthetic fracture ${ }^{c}$ & $0.3 \%$ & $£ 9569$ & $£ 6302$ & $£ 12,835$ & $<0.001$ \\
\hline Hip luxations ${ }^{\mathrm{d}}$ & $0.1 \%$ & $£ 14,266$ & $£ 7630$ & $£ 20,902$ & $<0.001$ \\
\hline Sequelae of fractures of the femur ${ }^{\mathrm{e}}$ & $0.2 \%$ & $£ 8463$ & $£ 3545$ & $£ 13,381$ & $<0.001$ \\
\hline Constant & & $£ 10,551$ & $£ 10,351$ & $£ 10,753$ & $<0.001$ \\
\hline No. of observations & & 30,282 & & & \\
\hline Residual degrees of freedom & & 30,261 & & & \\
\hline Link test ( $p$ value for yhat square) & & 0.41 & & & \\
\hline AIC & & 20.98 & & & \\
\hline
\end{tabular}

${ }^{\mathrm{a}}$ ICD 10 codes T81.0, T81.4 and T84

${ }^{\mathrm{b}}$ ICD 10 codes M84.9-M84.2

${ }^{\mathrm{c}}$ ICD 10 code M96.6

${ }^{\mathrm{d}} \mathrm{ICD} 10$ code $\mathrm{S} 73.0$

${ }^{\mathrm{e}} \mathrm{ICD} 10$ code $\mathrm{T} 93.1$ 
Although previous studies have reported costs of hip fracture in the UK, few were based on patient-level data or on recent populations. Moreover, previous cost estimates have been mostly informed by studies using small sample sizes (between 10 [14] and 2427 patients [15]), and using a variety of time horizons from initial discharge following acute admission [16-19] up to 12 months post admission [14, 15]. When the results of these previous studies were inflated to 2012/ 2013 prices, we also found considerable heterogeneity across them, with estimates of hospitalisation costs ranging from $£ 5083$ [15] to $£ 16,452$ [17]. Wide variability was also present in the reported 1-year costs after hip fracture, with estimates between $£ 6176$ [15] and $£ 20,470$ [14] in studies focusing only on women with hip fractures. Also, one study estimated the marginal 1-year costs to be $£ 4222$ higher per women with hip fracture compared to women without hip fracture [15] which is considerably lower than what we found in our study. In contrast, a recent UK study, based on 8208 patients, estimated the index hospitalisation cost of a hip fracture to be similar to our estimates (£8330) [20] and the 1-year costs to be £12,475 higher compared to the year pre-fracture, which is slightly higher than our estimate $(£ 10,860)$. However, the sample used in this study was younger than the typical UK hip fracture population, with the broader inclusion criteria (ICD-10: S72.0-S72.9 and M84.4, all ages, all admissions) resulting in a patient sample with a lower age at admission (mean 79 years) compared to our cohort (83 years) and the UK hip fracture audit data [21]. Furthermore, the proportion of patients with dementia at index fracture was considerably lower than in our cohort (12 vs. $18 \%$ ), suggesting that patients admitted from a care home may have been unrepresented, which may also explain the small proportion of patients being discharged to a care home following hip fracture (4.4\% vs. $18.0 \%$ in our study) [20]. Hence, our study contributes significantly to the evidence base regarding hip fractures by identifying and following a population of 33,172 patients with hip fractures up to 2 years before and after the index event.

We found the hospital costs to be high in the first 6 months after hip fracture, falling thereafter to levels of expenditure similar to the year before fracture. The same cost profile was observed in patients with a second hip fracture; however, initial admission costs were higher in the second fracture compared to the first. Acute hospitalisation costs due to index fracture accounted for $61 \%$ (£8663) of total 1-year costs and these costs were similar between first and second hip fracture, representing about 20 days of inpatient stay. Hospital costs in the year following hip fracture were estimated to be $£ 14,264$, representing 36 days of inpatient stay, with the majority of costs being associated with hip fracture-related hospitalisations $(75 \%)$. Furthermore, the 2 -year costs at $£ 16,289$ show that the majority of costs $(88 \%)$ occur in the year after the index hip fracture. Comparing costs before and after hip fracture showed these to gradually increase in the last
6 months prior to fracture, suggesting a worsening in health that may be associated with the risk of fracture. Such a pattern in costs is consistent with what has been reported in diseases such as stroke [22]. Also, men incurred higher hospital costs following a hip fracture compared to women, even after adjusting for several covariates. This is of concern as men are more likely to be underdiagnosed and have lower treatment uptake rates for osteoporosis before and after a fragility fracture compared to women [23].

Using the annual number of incident hip fracture cases, we were able to extrapolate our findings to the UK as a whole and estimate the cost to the hospital services in the year of the fracture. This was estimated to be $£ 1131$ million a year, and if incidence is to rise by $32 \%$ in 2025 [2], the hospital costs within the year of the fracture will increase to $£ 1493$ million a year. Furthermore, given the high marginal annual costs of hip fracture per patient $(£ 10,964)$, there is a considerable economic incentive to fund research aimed at identifying costeffective ways of improving the uptake of osteoporosis therapies and the implementation of embedded care pathways across healthcare services to effectively reduce avoidable fractures. Such data would aid decision makers implement policy decisions at a local and national level. A potential costeffective approach is through the implementation of coordinated approaches to fracture prevention such as fracture liaison services (FLS) [23, 24]. The Glasgow Fracture Liaison Service [25] reported that for every 1000 patients with a fragility fracture assessed by FLS, 18 fragility fractures (including 11 hip fractures) were prevented. This equates to potential savings of $£ 120,604$ per 1000 patients from the hip fractures averted alone. However, the savings could be potentially higher, as non-hip fractures, given their higher frequency, lead to greater health resource utilisation as measured by days of hospitalisation (2.9 times greater), community rehabilitation and nursing home care than hip fractures [26]. Another major consequence of fragility fractures is the consequent increases in non-health care costs, resulting from the use of social care services, admission to care homes, and provision of unpaid care by friends and relatives [27]. Further research is needed to determine these costs for both hip and non-hip fragility fractures.

The main predictors of first year costs were found to be mostly events related with hip fracture. Having a second hip fracture in the same year as the index fracture was associated with higher costs (£9198). A major focus for preventative therapy is targeted use of osteoporosis therapies that reduce the risk of re-fracture through an FLS [28-30]. However, the reduction in fracture risk from pharmacological therapies typically takes between 6 and 12 months of adherent therapy. This has two important implications. Firstly, we need to ensure that those eligible for osteoporosis therapy are initiated as early as possible after fracture and are monitored for short- and long-term adherence to therapy. This is captured by FLS 
standards developed by the International Osteoporosis Foundation [31]. Secondly, further evidence is needed to inform which specific rehabilitation-based interventions can reduce this early re-fracture risk after the index hip fracture. Given that a significant proportion of patients present with cognitive impairment, further research is needed to identify the most effective and cost-effective rehabilitation pathways for these patients [6].

It is also important to consider the impact of hip fracture on mortality. We found this to be high in our patient cohort during the first year post-fracture $(9.4 \%$ at 30 days and $31.2 \%$ at 1 year) and similar to previous UK studies where mortality ranged from 4.5 to $11.5 \%$ at 30 days and 28.7 to $33 \%$ at 1 year $[32,33]$. Furthermore, a recent systematic review reported the excess mortality in the hip fracture population to be at least double of what was reported for age-matched general populations [32]. Hence, designing and implementing costeffective management pathways and strategies focusing on reducing the risk of (re)fracture may not only result in potential healthcare cost-savings from preventing fracture(s) but also in life-expectancy gains. Finally, we found mortality to be different between male and female patients both at 30 days and at 1 year post-fracture. Again, this was consistent with previous work where male patients were reported to have at least twice the risk of death compared to female patients [32]. However, further research is required to examine the contribution of co-morbidities and other risk factors both in terms of excess mortality compared to the general population and gender differences.

In addition to the above, we recognise the following limitations. The hospital data were confined to a single region in the UK. However, this region has a representative rate of hip fracture cases with similar gender and age distribution as the rest of the UK [21]. Furthermore, the length of stay of index admission of a hip fracture is similar to that reported across the UK (19 vs. 20 days in 2012) [21] and, by capturing actual NHS activity, our results are strongly generalizable. Although datasets such as HES capture key variables influencing costs of hospital stay such as diagnosis and procedures during episodes of hospitalisation, they are not comprehensive in recording other morbidity and severity measures. Nonetheless, the validity of the HES dataset in identifying hip fracture cases has been shown to be very high [21]. Furthermore, the ascertainment of diagnosis and co-morbidities occurs mostly in patients with admitted patient care (inpatient stay or day cases), and a better understanding is required of the reasons for outpatient and emergency contacts. Also, it would have been useful to have linked hospital data with primary, community and social care records and estimate the costs beyond the hospital setting. This is, however, very limited with the current administrative datasets in the UK. Nonetheless, an approximation of the care home costs was possible. We estimated the average cost of a stay in a care home to be $£ 26,203$ for those patients admitted to one $(24.4 \%$ of whole cohort, with a mean of 245 days in care home at the cost of $£ 750$ per week). Hence, across all hip fracture cases, the care home costs would have averaged $£ 6299$ per patient, which would have increased the total costs of hip fracture to $£ 20,563$ in the first year and accounted for almost a third of total costs. Hence, despite these limitations, the quality of the dataset and the large sample size allowed us to make robust estimates of the hospital costs of hip fracture and the impact of patient characteristics such as age, gender and income deprivation and hip fracture-related complications.

In conclusion, our results show the impact of the first and second hip fracture on hospital costs and its predictors in the UK. Our results highlight the impact of complications following initial hospital discharge as a main driver of costs and the importance of preventing hip re-fractures. This study will be useful to commissioners, providers and researchers estimating the long-term cost-effectiveness of interventions for the prevention and management of these conditions such as an FLS.

Conflicts of interest J.L. reports no conflict of interest.

A.M.G. reports no conflict of interest.

D.P.A. has received unrestricted research and educational grants from AMGEN.

N.A. reports personal fees from Merck, grants and personal fees from Roche, personal fees from Smith and Nephew, personal fees from QMed, personal fees from Nicox, personal fees from Flexion, personal fees from Bioiberica and personal fees from Servier.

C.C. has received consultancy, lecture fees and honoraria from AMGEN, GSK, Alliance for Better Bone Health, MSD, Eli Lilly, Pfizer, Novartis, Servier, Medtronic and Roche.

M.K.J. has received in the last 5 years honoraria for travel expenses, speaker fees and/or advisory committees from Lilly UK, Amgen, Servier, Merck, Medtronic, Internis, Consilient Health and Jarrow Formulas. He also serves on the Scientific Committee of the National Osteoporosis Society and International Osteoporosis Foundation.

A.J. has received consultancy, lecture fees and honoraria from Servier, UK Renal Registry, Oxford Craniofacial Unit, IDIAP Jordi Gol, and Freshfields Bruckhaus Deringer, has held advisory board positions (which involved receipt of fees) from Anthera Pharmaceuticals, Inc., and received consortium research grants from ROCHE.

Open Access This article is distributed under the terms of the Creative Commons Attribution-NonCommercial 4.0 International License (http://creativecommons.org/licenses/by-nc/4.0/), which permits any noncommercial use, distribution, and reproduction in any medium, provided you give appropriate credit to the original author(s) and the source, provide a link to the Creative Commons license, and indicate if changes were made.

\section{References}

1. Johnell O, Kanis JA (2006) An estimate of the worldwide prevalence and disability associated with osteoporotic fractures. Osteoporos Int 17:1726-1733

2. Hernlund E, Svedbom A, Ivergard M, Compston J, Cooper C, Stenmark J, McCloskey EV, Jonsson B, Kanis JA (2013) 
Osteoporosis in the European Union: medical management, epidemiology and economic burden. A report prepared in collaboration with the International Osteoporosis Foundation (IOF) and the European Federation of Pharmaceutical Industry Associations (EFPIA). Arch Osteoporos 8:136

3. Burge RT, Worley D, Johansen A, Bhattacharyya S, Bose U (2001) The cost of osteoporotic fractures in the UK: projections for 2000 2020. J Med Econ 4:51-62

4. Stevenson MD, Davis SE, Kanis JA (2006) The hospitalisation costs and out-patient costs of fragility fractures. Women's Health Med 3:149-151

5. Dolan P, Torgerson DJ (1998) The cost of treating osteoporotic fractures in the United Kingdom female population. Osteoporos Int 8:611-617

6. National Institute for Health and Care Excellence (2011) Hip fracture: the management of hip fracture in adults. NICE guidelines CG124. https://www.nice.org.uk/guidance/cg124

7. Drew S, Sheard S, Chana J, Cooper C, Javaid MK, Judge A (2014) Describing variation in the delivery of secondary fracture prevention after hip fracture: an overview of 11 hospitals within one regional area in England. Osteoporos Int 25:2427-2433

8. Health \& Social Care Information Centre (2014) Methodology to create provider and cip spells from HES APC data. http://www. hscic.gov.uk/media/11859/Provider-Spells-Methodology/pdf/ Spells_Methodology.pdf

9. Health \& Social Care Information Centre (2013) Casemix Grouper. http://www.hscic.gov.uk/casemix-grouper

10. Department of Health (2013) NHS reference costs 2012 to 2013. https://www.gov.uk/government/publications/nhs-reference-costs2012-to-2013

11. Lin DY (2000) Linear regression analysis of censored medical costs. Biostatistics 1:35-47

12. Charlson ME, Pompei P, Ales KL, MacKenzie CR (1987) A new method of classifying prognostic comorbidity in longitudinal studies: development and validation. J Chronic Dis 40:373-383

13. National Joint Registry (2013) OPCS codes relevant to procedures recorded in the NJR. Version 3. http://www.njrcentre.org.uk/njrcentre/ Portals/0/Documents/England/Data\%20collection\%20forms/ OPCS $\% 20$ Procedure $\% 20$ codes $\% 20$ relevant $\% 20$ to $\% 20$ NJR.pdf

14. Iglesias CP, Manca A, Torgerson DJ (2009) The health-related quality of life and cost implications of falls in elderly women. Osteoporos Int 20:869-878

15. Gutiérrez L, Roskell N, Castellsague J, Beard S, Rycroft C, Abeysinghe S, Shannon P, Robbins S, Gitlin M (2011) Study of the incremental cost and clinical burden of hip fractures in postmenopausal women in the United Kingdom. J Med Econ 14:99107

16. Kazi HA, Acharya A (2011) Comparison of trauma and elective income in a district general hospital. BJMP 4:a440

17. Lawrence TM, White CT, Wenn R, Moran CG (2005) The current hospital costs of treating hip fractures. Injury 36:88-91, discussion 92

18. Sahota O, Morgan N, Moran CG (2012) The direct cost of acute hip fracture care in care home residents in the UK. Osteoporos Int 23: 917-920
19. Thakar C, Alsousou J, Hamilton TW, Willett K (2010) The cost and consequences of proximal femoral fractures which require further surgery following initial fixation. J Bone Joint Surg Br Vol 92-B: 1669-1677

20. Lambrelli D, Burge R, Raluy-Callado M, Chen SY, Wu N, Schoenfeld MJ (2014) Retrospective database study to assess the economic impact of hip fracture in the United Kingdom. J Med Econ 17:817-825

21. National Hip Fracture Database (2013) National report 2013. www.nhfd.co.uk

22. Luengo-Fernandez R, Gray AM, Rothwell PM, Oxford Vascular S (2012) A population-based study of hospital care costs during 5 years after transient ischemic attack and stroke. Stroke 43:33433351

23. Ganda K, Puech M, Chen JS, Speerin R, Bleasel J, Center JR, Eisman JA, March L, Seibel MJ (2013) Models of care for the secondary prevention of osteoporotic fractures: a systematic review and meta-analysis. Osteoporos Int 24:393-406

24. Mitchell PJ (2011) Fracture Liaison Services: the UK experience. Osteoporos Int 22:487-494

25. McLellan AR, Wolowacz SE, Zimovetz EA, Beard SM, Lock S, McCrink L, Adekunle F, Roberts D (2011) Fracture liaison services for the evaluation and management of patients with osteoporotic fracture: a cost-effectiveness evaluation based on data collected over 8 years of service provision. Osteoporos Int 22:2083-2098

26. Ioannidis G, Flahive J, Pickard L et al (2013) Non-hip, non-spine fractures drive healthcare utilization following a fracture: the Global Longitudinal Study of Osteoporosis in Women (GLOW). Osteoporos Int 24:59-67

27. Hansen L, Mathiesen AS, Vestergaard P, Ehlers LH, Petersen KD (2013) A health economic analysis of osteoporotic fractures: who carries the burden? Arch Osteoporos 8:126

28. Eisman JA, Bogoch ER, Dell R et al (2012) Making the first fracture the last fracture: ASBMR task force report on secondary fracture prevention. J Bone Miner Res 27:2039-2046

29. Marsh D, Akesson K, Beaton DE et al (2011) Coordinator-based systems for secondary prevention in fragility fracture patients. Osteoporos Int 22:2051-2065

30. National Institute for Health and Care Excellence (2008) Alendronate, etidronate, risedronate, raloxifene, strontium ranelate and teriparatide for the secondary prevention of osteoporotic fragility fractures in postmenopausal women. NICE technology appraisal guidance TA161. https://www.nice.org.uk/guidance/ta161

31. Åkesson K, Marsh D, Mitchell PJ, McLellan AR, Stenmark J, Pierroz DD, Kyer C, Cooper C (2013) Capture the fracture: a best practice framework and global campaign to break the fragility fracture cycle. Osteoporos Int 24:2135-2152

32. Abrahamsen B, van Staa T, Ariely R, Olson M, Cooper C (2009) Excess mortality following hip fracture: a systematic epidemiological review. Osteoporos Int 20:1633-1650

33. Neuburger J, Currie C, Wakeman R, Tsang C, Plant F, De Stavola B, Cromwell DA, van der Meulen J (2015) The impact of a national clinician-led audit initiative on care and mortality after hip fracture in England: an external evaluation using time trends in non-audit data. Med Care 53:686-691 